\title{
Research on Fighting against Poverty based on Targeted Poverty Alleviation Strategy of Ya'an City
}

\author{
Yu He $\mathrm{He}^{1, \mathrm{a}}$ \\ ${ }^{1}$ Sichuan Agricultural University, Chengdu, Sichuan, China, 611130 \\ aemail
}

Keywords: Ya'an City, Countryside, Fighting Against Poverty

\begin{abstract}
Long-term economic and social development lags Ya'an City, Sichuan Province is therefore accurate poverty reduction strategy to promote a key ring. How to promote anti-poverty work in Ya'an, is directly related to the province's 2020 poverty reduction target could uncap smoothly, and its importance is self-evident. This article from the analysis of the special difficulties faced poverty Ya'an, analyzes the misunderstanding of Ya'an poverty from the six recommendations put forward specific measures to struggle against poverty.
\end{abstract}

\section{Introduction}

Although Ya'an is one of prefecture-level city in Sichuan Province, but long-term drag on the province's economic and social development. "City of inferior village" accurately reflects the Ya'an City in the past 10 years without substantial development, better city behind the fact that the province's state of county, township and village. Vigorously promoting the national and provincial level poverty reduction strategies precise opportunities, Ya'an if you can not seize the opportunity to develop and implement effective anti-poverty initiatives, poverty reduction will become dragging hind legs of a typical, triggering an even greater crisis.

\section{The Special Difficulties Ya'an Fighting against Poverty is Facing}

Long-Term Corruption Leads to Economic Development Lags behind Humpty. Between Bangladesh serving eight years, Ya'an severe economic and social development get stagnation and even retrogression. Located in the province's long-term total GDP ranks of cities and states countdown, coupled with serious corruption, the city not only poverty-stricken counties, townships and villages there is no long-term development, Yucheng city center is a few decades to a standstill. Poverty not only in rural areas, the number of urban poor is also gradually increasing. Since the concept of error and wrong policies of the leadership, as long as gold and silver mines do not relying on the city's tourism development concept of playing cards serious ecological unrealistic to leave large empty self-comfort, and lack of tourism potential, with supporting not on the tourism practitioners enthusiasm subsided, think fast in a short time to change the status quo, poverty is difficult to achieve, if not to develop and implement effective measures will drag on the province's poverty alleviation work, should pay close attention.

Natural Conditions of Poor Poverty Counties, Townships and Villages are Rigorous. Currently, Ya'an city faces the crucial task of poverty. Among them, the days of the county, Shimian, Baoxing traffic is extremely inconvenient for the status quo has been neither solved effectively take hours out of a county economic development is difficult. Coupled from 5.12 Wenchuan Earthquake, Lushan 4.20 after a strong earthquake, earthquake-prone city of Ya'an, secondary disasters continue to seriously affect the investment intentions of investors, and this can change the status of a non-human, anti-poverty significantly increased the difficulty.

The Available Poverty Alleviation Means Lack of Dealing with the Large-Scale Natural Calamities Poverty Continues to Impoverished Mechanism. The main means of large-scale poverty city has to respond to disasters caused by government bailouts, and rely heavily on all levels of government spending. Poverty-stricken areas is often disaster-prone areas, such as days of the county, Baoxing, Hanyuan, coupled with the difficulty of the original poverty sudden massive 
new poor, so poor areas can not afford the required local financial poverty investment and financial investment alone to deal with the problem of poverty disasters lack of long-term mechanism to solve the problem. Especially when some time after the disaster, disasters tend to be forgotten, however, poverty remains a significant problem has troubled people in disaster areas, disaster sustained measures to alleviate poverty becomes extremely important. Poverty means lack of response to the existing mechanisms for sustained poverty a large area of natural calamities caused by poverty.

Lack of Human Resources and Lack of Effective Leaders. Since Ya'an long stagnation, unable to retain talent has become an indisputable fact. From school children to university students, a large number of students' resources to flow to the area around Chengdu, Ya'an membership graduates choose to return to elegant little work. The city became the city left behind, not to mention the rural counties. At the same time, the leadership of Ya'an City and also constitute a serious impediment to development. Sacked officials Wei Hong, Xu Bangladesh, who have Ren Yaan party secretary, corrupt political ecology group events Humpty water dam, Pubugou other treatment ineffective so that the people of the long-term accumulation of discontent. Ya'an incumbent party secretary concurrently by the Deputy Governor, if this worked in ways that favor local development needs to be proven. In the battle against poverty, the absence of strong and effective leadership, the results are predictable.

\section{Misunderstanding of Ya'an Fighting against Poverty}

There are Some Defects in Regional Development-Oriented Poverty Reduction Policy Proposed by the Government. Currently, Ya'an municipal government good government in order to improve the poverty in the city's rural counties, proposes a regional development-poverty policy, the so-called regional development-based poverty refers to regional economic development as the core, promote overall economic development such a development policy mainly to develop some type of local resources can be used to enhance the economic means to achieve, but ignored the Ya'an city development seriously lagged behind the development of the individual points of fact alone utterly inadequate. Policy should not only remain in the "looks beautiful" level, should focus on achieving results. In the actual implementation process, the government pays more attention to the theory of publicity and the media effects of the policy, ignoring the "hard work" means. Repeatedly invited the media to rely solely on the bombing of reports on the effects of policies not only fail to solve the dilemma is not obvious, more likely to cause people's resentment. For example, a building Yucheng District Center City Chaoyang Street after the 4.20 earthquake in Lushan been tested for the D level dangerous, but it has not been dismantled, to date, actually painted facades and re-enabled, attracted condemning people one slice. State and alone reconstruction funds at the provincial level only in the hardest hit and the epicenter face-lift, but the fundamental problem lies in Ya'an city's development is seriously lagging behind, relying on the development model point to an area difficult to achieve tangible results.

Less Investment and Accumulation in Human Capital. In recent years, in order to better improve the poverty and achieve the poverty goal, the Government has invested a lot of financial help, but in keeping human initiative but unhelpful. Not only technical serious brain drain and even some of the cream of the civil service because of the treatment, housing, promotion difficulties and other practical problems involved in selecting the provincial authorities or other city states and other ways to leave open audition Ya'an, pursue other interests. Human poverty is the lack of a significant impact, as well as in financial and government institutions as well as construction of associated facilities at the same time, if long-term disregard the importance of talent and human resources, will be difficult to achieve economic development and improvement.

Rural Social Security System Is Imperfect. In addition there are some financial problems other than pro-poor policies, poor counties in rural social security system is also not perfect. Because of the city's large number of outflow of human resources for the social security system left behind far less population, especially in poor villages. In recent years, in order to improve social security in rural areas, has been put forward new rural cooperative medical care, rural social endowment 
insurance, basic social security, however, in practice, in addition to some of the more developed regions, many regions still do not enjoy these safeguards, then there socio-economic security standstill phenomenon. In some areas due to the earthquake and rebuild their homes have spent a lot of family income, once the disease, there have been caused by the poor, and even the phenomenon of returning to poverty.

\section{Suggestions for Fighting against Poverty of Ya'an}

Handle the Relationship between Economic Development and Environmental Protection. Ya'an good ecological environment can not be at the expense of social and economic development at the expense, but should both Guanghui, but also gold and silver mines. First, we should focus on the introduction of a number of low energy consumption, low pollution industrial projects, courageous first step towards the city's industrial development. This is to promote the city to carry out employment, but also be able to open local resources, so that people have something to do with living to do, rewarding investors with dry head. Taking into account the importance of environmental protection, industrial projects can choose to construct a relatively small number of inhabitants in the county and township level, but the prerequisite is to create a convenient traffic conditions. Secondly, standardize tourism development, strengthen supervision, change the "special pit tourists", "cheating" phenomenon, the guide "puerile" concept, to develop rural tourism, create a group of influential agricultural products, effective increase rural income people.

Strengthen the Management of Financial Funds. Especially the reconstruction funds, the whole society should publish origin and path. Relevant government personnel must strengthen supervision of funds for poverty alleviation, and thus ensure that every penny is spent wisely. Do less face, and image projects, do more people recognized the need to solve practical engineering, demolition of dilapidated buildings as soon as possible, to protect people's lives and safety. In addition, provincial and municipal some items for examination and approval, supervision should be promptly exiled time money, not to delay the emergence of exile, dragged white spoon phenomenon, thereby ensuring the proper implementation of poverty alleviation projects. It should also increase efforts to deal with corruption, not to the presence of worms in poverty ranks.

Improve the Social Security System in Rural Areas. For the city's young and basic labor migrant, staying mostly the old, weak, sick, shortage of labor and mountain cultivation, harvesting, transport, sell, there are certain practical difficulties, the government should try to improve the social security system in rural areas, to effectively ensure that each poor households can enjoy a basic right to social security, thus achieving poverty alleviation and anti-poverty purposes. Be sure to clear the deployment of better, if you do not carry it out are equal to zero. For spending a lot of money due to the reconstruction and poverty caused by the difficulties of returning to poverty groups to increase care assistance, and helping to carry out multi-channel, and effectively solve their practical difficulties.

Classification Develop the Poverty Reduction Programs. For Ya'an practical, pro-poor policy formulation must be classified, according to local conditions. Should be sub-county in the preparation of poverty reduction within the city embodiment, the number of poor households to determine the classification, population, structure and distribution, and task lists Requirements List menu. 261 poor villages in the city, it should ensure that each village has a responsible leadership, a support unit, a village-based working group, a "first secretary", a village-based agricultural workers, for it should be a strict management system and assessment methods. City counties (districts) should focus on "who support", "who help", "how to help", "How to back" the progress of four stages corresponding to the establishment of four ledger, making identification of poor households, helping, poverty accounts have to be investigated, evidence-based, to ensure accountability in place.

Promote Poverty Target Employment Support. In anti-poverty work, support measures should focus through skills training, employment assistance, employment and entrepreneurship, social security, employment and other human intelligence, human social services and poverty reduction the depth of integration. We should first focus on skills training to enhance the employability of the poor masses. Around the industrial, tourism and real resources to carry out Chinese cooking, pastry 
chefs, housekeeping, knitting craft workers, civilian electricians, welders and other vocational skills training. Second is to build a platform of employment, poor people increase employment opportunities. Should carry out special recruitment activities, carry out fair type, fixed type, festival-style recruitment, timely release of business and employment information and create more jobs for poor families' personnel, increase employment capacity and personnel to help poor families to achieve the transfer of employment. Difficult for poor people to achieve employment section, you can develop a number of public service jobs and other cleaning job placement, give some subsidies for public service positions, pushing poor families achieve stable employment, increase income levels.

Establish Disaster Poverty Alleviation System and Broaden the Channels for Poverty Reduction. For disaster poverty, the government is often the fire-fighting poverty, disposable poverty, persistent poor. From the future should focus on disaster prevention, disaster relief plan when the Poverty Reduction and post-disaster recovery and disaster persistent poverty develop measures to alleviate poverty in a bid to establish disaster Poverty system. Furthermore, it should guard against natural risks through insurance means to prevent large-scale disaster caused by poor back into poverty and overcome the potential moral hazard is an important means to ensure sustained poverty reduction. While dispersing disaster risk through insurance, it can also reduce the financial pressure in front of a large national disaster relief. And one of sustainable and effective means of people out of poverty through sustainable financial operation is also supported.

\section{Acknowledgements}

Fund Project: Sichuan Ya'an City Federation of Social Sciences 2016 Project "Fight against Poverty of Ya'an City".

Dual-Branch Plan of Association of Social and Political Project of Sichuan Agricultural University "Socialist Culture Research with Chinese Characteristics"

\section{References}

[1] Sichuan prominent anti-poverty rural poverty must start with [EB / OL] from seven. http: / / tieba. baidu. com / f kz = 168468370 .

[2] Zhuangtian Hui, Yu Chongyuan. New Stage National Farmers in poor areas of Sichuan Poverty Alleviation and Development Needs Analysis [EB / OL]. (2012--05--28). http: / / www. xbnc. org / Article_Show. asp? Article ID = 5705 .

\section{Author Introduction}

Yu He * (1984- ), the corresponding author, master of laws, the lecturer of Marxism College in Sichuan Agricultural University , the research direction is the Sinicization of Marxism. 